\title{
Communicative Codes of Visual Nature for Business Communications
}

\author{
Kiselev V.M.* \\ Plekhanov Russian University of Economics \\ Moscow, Russia \\ e-mail: kisselev.vm@mail.ru
}

\author{
Savinkov S.V. \\ Plekhanov Russian University of Economics \\ Mendeleev Russian University of Chemical Technology \\ Moscow, Russia \\ e-mail: savinkov.sv@gmail.com
}

\author{
Meshkov V.R. \\ Moscow, Russia \\ e-mail: meshkov_vr@mail.ru
}

\begin{abstract}
The use of communication codes for efficiency communication programming (infogramming) is an innovative approach to soft support for management decisions. This approach was proposed by Richard $H$. Thaler and named Nudge. However, the author of this approach did not offer efficiency tools for the practical application of this innovation in supporting solutions. We offer an author's tool for the practical implementation of Nudge - infographic, so to speak- information programming of decision makers to transform decisions from the irrational field of the mind to the rational one through communication codes of a visual nature. The practitioners require communication code to form such communications. They are certainly different for divers target environment. Their identification requires complex marketing research. Recently, a scientific and methodological discussion has been held on the relevance of the results obtained through sociological surveys as a method of marketing research. In our opinion these discussions lead to a fair conclusion about the low relevance of the results of opinion polls due to a number of factors affecting this parameter. The most convincing explanations about the traps that the researchers introduce the method of opinion polls are reflected in the work of recognized authorities in marketing research. An alternative to the methodology of the opinion poll is the in-depth interview method, which assumes, in contrast to the method of opinion polls, a qualitative study that answers the questions of "how", "in what way", etc. At the same time, qualitative research has its own traps, consisting in a small number of respondents. As a rule, this number is about 3-6 people. For this reason, many researchers do not consider the results of such studies to be practically valuable. In this regard, the authors of this article face the task of proposing a hybrid method that is quantitative in terms of the number of respondents and qualitative in terms of avoiding the traps of social surveys. The authors confirm the practical value of the proposed hybrid method by comparing the results of quantitative and qualitative research methods of the same target environment. The metaphor extraction methodology
\end{abstract}

proposed by Gerald Zaltman (ZMET) was used in order to escape the traps of quantitative research methods.

Keywords - marketing research, quantitative and qualitative research, focus groups, in-depth interviews, verbal associations, ZMET, communication codes

\section{INTRODUCTION}

The use of projection methods of marketing research is caused by the need to obtain from the respondents such information about themselves that it is impossible to obtain when conducting a direct survey. The main tool of this kind of research is an indirect survey form that encourages respondents to express their hidden beliefs, attitudes, or feelings about the issue under discussion [1]. Using this approach to the survey, there is no fear of incorrect answers, as the respondents are not aware of the true purpose of the survey and cannot distort their answers if they want to intentionally deceive the researcher. A significant advantage of this kind of research is precisely that they reveal the hidden beliefs of respondents that appear only at the subconscious level of the human mind, bypassing volitional attitudes [1].

In this group of studies, among a number of other methods, the most preferable in the practice of marketing research was found to be associative methods, involving the testing of respondents using test drawings. Such studies are characterized as qualitative with an indirect survey form.

In order to confirm and clarify the results of quantitative projective-associative research we used qualitative types of marketing research - a focus group and in-depth interviews. The focus group provides for an unstructured interview which the moderator takes from a small group of respondents that is homogeneous in terms of key parameters in order to get an 
idea of what the participants think about the issues proposed for discussion. The free nature of the discussion allows getting personal judgments of each of the participants in the focus group [1]. The entire discussion is recorded by video for subsequent analysis in order to detect insincerity in the answers using non-verbal statements and to remove the latter from the final result. The replies of the respondents are mainly non-standard in nature, for which they require additional qualitative research for example by the in-depth interview method. The in-depth interview method with the focus group is also an unstructured direct method of communicating with respondents but unlike the latter it assumes a personal character. Communication in an in-depth interview due to its unstructured nature of the statements of the interviewees are depending on their personal qualities and emotional mood and lasts indefinitely. To clarify personal assessments and judgments a script is used based on among several possible alternatives the free and laid-back symbolic nature of judgments of phenomena or terms from the personal environment of respondents, their worldview, culture and education which may not be available in the focus group method due to the tendencies of some of its members towards conformism - the desire to follow the prevailing opinion of all its participants, or, on the contrary, non-conformism - to mirror their opinions. This approach allows identifying the hidden meaning of the analyzed objects related internal experiences, relationships, judgments and statements [1]. The in-depth interview scenario assumes among other things conversation based on creative imagination to clarify their relationship to the tested words randomized in the order of their discussion in person-to-person communication. This list of test words also includes neutral words that are not relevant to the subject being analyzed. Such words allow determining the sincerity of the respondents, their emotional state at the time of communication which lasts sometimes for an hour and a half. During such personal conversations respondents' answers are supposed to be thoughtless and free from structuring. The response time to interviewers' questions is recorded by video. This technique allows establishing the true hidden feelings and attitudes of respondents to the analyzed test words with the exception of fictitious judgments.

In this regard the method of in-depth interviews is interfaced with the method of verbal associations (refers to projection methods) when interviewees are invited to express their opinion on the subject being analyzed and make a choice of one of the list of words proposed by the interviewer or arrange them in a certain order. They are distinguished only by the obviousness of the purpose of research for respondents: the purpose is obvious in an in-depth interview while in the method of verbal associations it is not which is a group attribute of projection research methods [1]. When the interviewees forget about the purpose of the study in view of the length of the conversation time and the randomization of the order of the words being tested (objects, categories, phenomena) or their emotional arousal in this case the indepth interviews are transformed into verbal associations especially since both methods belong to the group of qualitative studies and pursue the same goals. A common problem of all the above survey methods in marketing research is the protection of the result from conscious or unconscious distortion of respondents' answers [2-10]. One of the efficiency tools of this kind of protection is the "Metaphor Identification Technique", developed by Harvard Business School (USA) professor Gerald Zaltman, designated by him with the term "ZMET" (The Zaltman Metaphor Elicitation Technique) $[11,12]$. The method was patented by the author in 1995 [13].

The essence of the ZMET method is the fact that people think with images in their subconscious and not with the help of words. Therefore to identify their true judgments it is advisable to form the responses of respondents in the form of a choice of one of the proposed visual images. The researcher offers these images to respondents.

During the study the participants are invited to express their opinions (judgments, metaphors) using their chosen visual images, suggesting alternative shapes, sizes, colors and other parameters of visual nature. The development of this method involves the choice of alternatives also taste, olfactory, tactile, sound nature. All these sensual incarnations of the inner life of the respondents which can act as a trigger when choosing a specific trading offer including one or more of these reference signals-images.

These metaphors can vary in depth of placement in the subconscious of people: superficial (phraseological units) or deep (archetypes). Superficial metaphors located in the near field of the subconscious can "draw out" the deep ones hidden in the depths of the human mind not used by people in ordinary life practice. Metaphors related to a specific subject area are called thematic with which people operate in life practice related to the chosen topic of activity. All metaphors facilitate the sensory recall of people which contributes to their unconscious consumer choice. The ZMET method has won the recognition of many researchers [14, 15]. It was believed that it does not replace traditional marketing tools, but completes their arsenal. This method is especially good at a commercial offer of an irrational nature for example services. Well-known marketing theorists and practitioners refer to this method. Of course it is clear that without understanding the scope of the unconscious of their target customers questions of quantitative research methods will also be ineffective [16]

\section{METHODOLOGY}

The goal of marketing research was formulated among the students who are the first-year study at Plekhanov Russian University of Economics in order to build efficiency communications with applicants entering the economic universities.

The indicated goal was to identify the main cultural codes that influence their involvement in one of many economic universities. Hypothetically, the knowledge of such codes will allow the university to efficiently attract a youth audience after graduating from secondary schools to continue its education at the Plekhanov Russian University of Economics.

The comprehensive marketing research was conducted to implement the designated goal [17]. At the first stage of the study they had the character of a quantitative questionnaire 
using the ZMET method. At this stage the studies carried out a structured approach: on the base of these questionnaires the respondents were asked to create an associative relationship with graphic images which according to the researchers have a very stable relationship with education, science, knowledge and the life values that these categories provide. To conduct a quantitative study, questionnaires were developed that placed a matrix of visual images (table head) and life values (table rows). Respondents had the opportunity of multiple choice by marking the fair, in their opinion, correspondence of images and values. The study was conducted in the fall of 2018. At the preliminary stage of the pilot tests, questionnaires were selected from a set of possible visual images (37 units) for study 7. A similar pilot test also reduced the list of life values, of which 18 were selected for study. Thus, the final matrix was a table with 7 visual images (the head of the table columns) and 18 values (the name of the table rows). The order of the analyzed images and values was randomized to avoid a systematic research error. The study was selective and the number of respondents was 600 people- first-year students in bachelor programs of various economic profiles. Filling out questionnaires took place at the beginning of in-line lectures in the presence of researchers. The time for filling out the questionnaires was a maximum of a quarter hour. The questionnaires were anonymous. The study was conducted in the classrooms of Plekhanov Russian University of Economics in the spring of 2018 as a part of the job for the Project funded by a grant of the Russian Foundation for Basic Research. The results of the quantitative survey were analyzed by the methods of mathematical statistics. Based on the results of the analysis an econometric model is constructed [17].

The specified model was tested by qualitative methods of marketing research on the base of focus group and of in-depth interviews. The use of qualitative research after quantitative to understand the results of the latter does not contradict the methodology of complex research [18].

A focus group was held with 12 respondents selected from the participants in the quantitative survey at the second stage of the complex research. The focus group scenario provided for discussion based on the 4 strongest visual images identified in the quantitative study. For each visual image several questions were compiled which were subsequently randomized. The research scenario included a discussion of 20 questions. The order of the issues discussed was randomized to avoid systemic research error. All actions were carried out during video recording on digital media. The participants were warned about this in advance. The recording of conversations was transcribed for subsequent analysis.

At the third stage of the complex research the most responding to the goals of the in-depth interview three participants (girls) were selected to further understanding the results of the previous stages of the research. Interviewees for in-depth interviews were carefully selected. Each of them showed independence of their own opinion the absence of signs of conformity and non-conformism. In addition students had different income, social status, place of birth and permanent residence. It is important that the professional interviewer was invited from outside and the respondent did not have a personal or official relationship with him. This precaution, as we know, prevents deliberately false answers. At the same time, a superficial (just before the start of the interview) acquaintance positively affected the emotional state of the interviewees allowed them to relax and feel comfortable. Three personal interviews were conducted with them in full compliance with the methodological requirements [18]. The study took place in the fall of 2018. If the participants found it difficult to answer a separate question from the interviewer then the question was deleted from the interview. The order of the issues discussed was randomized to avoid systemic research error. All three interviews were conducted with video recording on digital media so that during the analysis it was possible to take into account not only words but also facial expressions, gestures, body movements, and other non-verbal response parameters. The respondents were warned about this in advance. Digital recording of conversations was transcribed for subsequent analysis.

\section{RESULTS AND ITS DISCUSSION}

It was established that the hypothesis about the predictability of the type of psycho-emotional state among students through eye contact with visual images was confirmed for three of the seven tested visual images based on the conducted quantitative studies using the ZMET method. It was found that together with the main type of tested responses a plume of side alternatives is traced. This indicates that the visual images selected for communication are deeper emotionally saturated and penetrate deeper into the subconscious region of the mind of respondents. The methodological compliance of the study with generally accepted requirements allows extending the results to the entire general population of the target audience, which is the student community of the Plekhanov Russian University of Economics. With certain parameters of kinship of other contact classrooms, for example, applicants from other universities with the examined one it allows extending the results to them as well.

The main points identified as a result of the studies are that the tested images are perceived by the examined audience as:

- Bogatyr Ilya Muromets - protection (probability of manifestation $65 \%$ ) with a decrease in the level of fear, with concentration;

- Gorgon Medusa - frightening (probability of occurrence is $64 \%$ ) but it also leads to depression (probability of occurrence is $50 \%$ );

- An opened wallet with money - has two-fold responses: both a harbinger of loss (a probability of occurrence of $47 \%$ ) and a symbol promising a profitable acquisition (probability of occurrence of $46 \%$ ) which entails an uplift in mood (probability of occurrence of $46 \%$ ).

Other tested images showed an average strength in generating the tested psycho-emotional states. So, unlike expected, the images of M.V. Lomonosov and A.S. Pushkin did not confirm their hopes and cannot be recommended for use in communications with university entrants. 
The most frequently manifested types of values of higher education (the probability of manifestation is $64 \div 65 \%$ ) in this study, when in eye contact with the tested images, are feelings of fear and protection from fear. It is these values that are advisable to use to attract applicants to the university under analysis.

At the second stage of the complex study (focus group) it was established that the group agrees that the image of an open wallet with money generates a sense of joy and protection. At the same time a sense of security reduces fear.

At the third stage of a complex research (in-depth interview-word associations), the image of an open wallet as a value of accumulation like an unexpected find was also successfully confirmed. All three respondents showed that they had such an association.

Regarding the significance for higher education interviewees as a category of life values all three showed a low degree of such significance. An analysis of the video recording of the interview showed one of the squeamish grimaces on one of the participants when answering the question about the significance of higher education for her.

\section{CONCLUSIONS}

It was found based on the complex research that a quantitative study showed the statistical significance of three visual images in the value generation system of the analyzed student audience of which only one was confirmed in the two following varieties of qualitative research

Comparing the usefulness for researchers of various quantitative and qualitative marketing research, it should be noted that not all of their results are consistent with each other. At the same time the good convergence of the results was shown by the results of two varieties of marketing research of a qualitative nature. On this basis we argue that conducting quantitative research without quality is ineffective because their results can lead to the direction of researchers. With regard to the sequence of quantitative and qualitative studies it is advisable to conduct a separate study.

\section{References}

[1] R.H. Thaler, C.R. Sunstein, Nudge: Improving Decisions About Health, Wealth, and Happiness, Penguin Books, 2009, 312 p.

[2] R.H. Thaler, Misbehaving: The Making of Behavioral Economics, W.W. Norton \& Company, 2016, 432 p.

[3] N.K. Malhotra, Marketing Research: An Applied Orientation, 7th Edition. What's New in Marketing. Pearson, 2018, 896 p.
[4] A. Verma, 15 Market Research Mistakes to Avoid - How to succeed using market research? Independently published, 2018, $29 \mathrm{p}$.

[5] T. Langhans, The 7 Marketing Mistakes Every Business Makes (And How to Fix Them), Blah Blah Blah Publishing, 2003, 68 p.

[6] R.F. Hartley, C. Claycomb, Marketing Mistakes and Successes, 12th Edition, Wiley, 2014, 416 p.

[7] L. Leach, Marketing to Mindstates: The Practical Guide to Applying Behavior Design to Research and Marketing, Lioncrest Publishing, 2018, $256 \mathrm{p}$

[8] T.L. Hazzard, Top 7 Consumer Market Research Mistakes to Avoid. Inc.com. JUN 29, 2018. Retrieved from: https://www.inc.com/tracyleigh-hazzard/top-7-consumer-market-research-mistakes-to-avoid.html, Access date: 02.02.20.

[9] P. Hudson, 10 Market Research Mistakes You Need to Stop Making, Retrieved from: https://blog.flexmr.net/market-research-mistakes, Access date: 02.02.20.

[10] Top 10 Market Research Mistakes. Advertising, Marketing \& PR, Retrieved from: https://www.allbusiness.com/top-10-market-researchmistakes-3970-1.html, Access date: 02.02.20.

[11] G. Zaltman, How Customers Think: Essential Insights into the Mind of the Market 1st Edition, Harvard Business School Press, 2003, 323 p.

[12] G. Zaltman, UNLOCKED: Keys to Improve Your Thinking, Independently published, $2018,150 \mathrm{p}$.

[13] G. Zaltman, Metaphor elicitation method and apparatus, US Patent no. 5436830, G06F15/38, G06Q 30/02, 1995.

[14] D.A. Aaker, Marketing Research, Wiley, 2015, 760 p.

[15] J.J. Davis, Advertising Research: Theory \& Practice, 2nd Edition, Publisher: Pearson, 2011, 704 p.

[16] V.M. Kiselev, S.V. Savinkov, Yu.V. Syaglova "Visual support for management decisions through infographic", in Actual issues of marketing management and the use of innovative technologies in solving problems of socio-economic development of Russia. Appendix to the scientific journal "Economics, Business, Banks", 2017, pp. 121-136. ISSN 2304-9596. RSCI:29204317. Retrieved from: http://apps. webofknowledge.com/full_record.do?product=RSCI\&search_mode=Ge neralSearch\&qid $=3 \& \mathrm{SID}=\mathrm{T} 1 \mathrm{FD} 3 \mathrm{GkgIcJ}$ NiwLCVI\&page $=1 \& \mathrm{doc}=2$

[17] V.M. Kiselev, L.V. Plushcheva, S.V. Savinkov "The study of the influence of colors in marketing communications: empirical and experimental figures", in Globalization and its socio-economic consequences. 16th International Scientific Conference, 5th -6 th October 2016, Proceedings, Part IV, ZU - University of Zilina, Rajecke Teplice, Slovak Republic, pp. 1720-1728. Retrieved from: http://apps. webofknowledge.com/full_record.do?product=UA\&search_mode=Gene ralSearch\&qid=1\&SID=N1 arSJE11MG7ZqcJhOy\&page $=1 \&$ doc $=4 \& \mathrm{ca}$ cheurlFromRightClick=no;http://ke.uniza.sk/sites/default/files/content_fi les/proceedings_part_iv_0.pdf.

[18] V.M. Kiselev, S.V. Savinkov, V.A. Terentyev, "Scientometric evaluation of visual solutions for branding", in Globalization and its socio-economic consequences. 16th International Scientific Conference, 5th - 6th October 2016, Proceedings. Part II. ZU - University of Zilina, Rajecke Teplice, Slovak Republic, pp. 892-897. Retrieved from: http://ke.uniza.sk/sites/default/files/content_files/proceedings_part_ii_0.pdf. http://apps.webofknowledge.com/full_record.do?product=UA\&search_ mode $=$ GeneralSearch $\&$ qid $=1 \&$ SID $=\bar{N} 1$ arSJE 11 MG7ZqcJhOy $\&$ page $=1$ $\&$ doc $=3 \&$ cacheurlFromRightClick $=$ no 